\title{
Meeting of the Eastern Mediterranean Research Ethics Review Committee $^{1}$
}

${ }^{1}$ This report is extracted from the Summary report on the Meeting of the Eastern Mediterranean Research Ethics Review Committee, Cairo, Egypt, 22-23 October 2017 (http://applications.emro.who.int/docs/IC_Meet_Rep_2017_16772_EN.pdf?ua=1, accessed 17 April 2018).

Citation: WHO Regional Office for the Eastern Mediterranean. Meeting of the Eastern Mediterranean research ethics REview committee. East Mediterr Health J. 2018;24(3):319-320. https://doi.org/10.26719/2018.24.3.319

Copyright (c) World Health Organization (WHO) 2018. Some rights reserved. This work is available under the CC BY-NC-SA 3.0 IGO licence (https://creativecommons.org/licenses/by-nc-sa/3.o/igo).

The World Health Report 2013: Research for Universal Health Coverage (1) emphasized WHO's role in advancing research that addresses the dominant health needs of its Member States, supporting national health research systems, setting norms and standards for the proper conduct of research and accelerating translation of research findings into health policy and practice. In 2010, the $63^{\text {rd }}$ World Health Assembly (2) recognized the contribution of research to development of solutions to health problems and endorsed the WHO strategy on research for health. This strategy aims to ensure the highest norms and standards of good research within WHO, and provide support to Member States in taking relevant actions to strengthen national health research systems.

Research proposals recommended for WHO funding through different grant schemes require methodological and ethical review. In 2017, the Eastern Mediterranean - Research Ethics Review Committee (EM/RERC) was reformulated with the essential function to review the protocols of all health research projects involving human subjects submitted to WHO for funding in the Region. The Committee has the authority to verify that ongoing studies comply with the Organization's policies and regulations for conduct of health research in the Region, and it may suspend or terminate approval for ongoing studies under its jurisdiction.

In order to ensure compliance with $\mathrm{WHO}$ policies and regulations, the EM/RERC members meet on an annual basis to follow up WHO-supported health research in the Region. The 2017 annual meeting was organized by the WHO Regional Office for Eastern Mediterranean (WHO/ EMRO) from 22 to 23 October 2017 at the Regional Office in Cairo, Egypt. The objectives of the meeting were to:

- review RERC's work during 2016-2017;

- agree on modalities for taking forward the recommendations of recent meetings; and

- plan future work in light of the Programme Budget for 2018-2019.

The meeting was chaired by Professor Gamal Serour, Director, International Islamic Center for Population Studies and Research (IICPSR), Egypt.

\section{Summary of discussions}

The EM/RERC has two mandates: reviewing the health research proposals involving human subjects subjected to funding by WHO to ensure protecting dignity, integrity, human rights, safety and well-being of all human participants in research; and ensuring compliance with the International Ethical Guidelines for Health-Related Research Involving Humans (3).

During discussions, participants highlighted the need for bioethics capacity-building in the Region, including further capacity development of RERC members (themselves) through possible online courses and participation in WHO activities. They also discussed the situation of multi-centre studies and exemptions versus expedited review.

The recommendations of the 2016 RERC meeting were reviewed and discussed with participants. Detailed statistics were presented including the number of reviewed proposals from projects funded under the Improving program Implementation through Embedded Research (iPIER), Research in Priority Areas of Public Health (RPPH); and Tropical Disease Research (TDR) over the years.

The RERC checklists for reviewers and principal investigators (PIs) were thoroughly reviewed based on the modifications recommended by the RERC during its 2016 meeting (4). More amendments were made to the RERC checklist for PIs, especially for the sections on minors (less than 18 years old), pregnant women and emergency contexts.

The Committee reviewed the recommendations of two recent meetings and their implications for its work, i.e. the Regional Bioethics Summit for the Eastern Mediterranean/Arab States, held in Muscat, Oman, April 2017 (5); and a workshop on teaching bioethics and research ethics, held in Damascus, Syrian Arab Republic, August 2017 (6). Both meetings focused on the functions and work of national bioethics and ethics committees and recommended strengthening their internal mechanisms, role in promoting bioethics, health research ethics, coordination and cooperation. The Committee discussed ways to take forward the recommendations of these meetings and proposed the following actions.

\section{Recommendations}

Based on the discussions during the meeting, the following actions were recommended for the Committee and WHO Secretariat.

1. Developing terms of reference for the RERC, including the duration of assignment (considering the model of the tuberculosis Green Light Committee). 
2. Developing a list of FAQs to be posted online in relation to ethical review as a guide for research applicants.

3. Developing a template for informed consent forms, including for genetic and biobank-related research, and for RERC clearance.

4. Identifying a modality to link the RERC with national committees.
5. Encouraging principal investigators of WHOfunded proposals to publish their papers and make manuscript submission conditional with receiving payments.

6. Considering holding side meetings for the RERC during global and regional bioethics summits.

\section{References}

1. World Health Organization. World Health Report 2013: research for universal health coverage. Geneva: world Health Organization; 2013 (http://www.who.int/whr/2013/report/en/).

2. Sixty-third World Health Assembly. Geneva, Switzerland 17-21 May 2010 (http://www.who.int/mediacentre/events/2010/wha63/ en/).

3. Council for International Organizations of Medical Sciences (CIOMS). International ethical guidelines for health-related research involving humans. Geneva: CIOMS; 2016 (https://cioms.ch/wp-content/uploads/2017/o1/WEB-CIOMS-EthicalGuidelines. pdf).

4. WHO Regional Office for the Eastern Mediterranean (EMRO). Meeting of the Eastern Mediterranean Research Review Ethics Review Committee. Cairo: EMRO; 2016 (http://www.emro.who.int/rpc/rpc-news/meeting-of-the-eastern-mediterranean-research-review-ethics-review-committee.html).

5. WHO Regional Office for the Eastern Mediterranean (EMRO). Eastern Mediterranean/Arab states regional summit of national ethics and bioethics. Cairo: EMRO; 2017 (http://www.emro.who.int/rpc/rpc-events/regional-summit-of-national-ethics-and-bioethics-committees.html).

6. UNESCO \& WHO. Workshop “Teaching Bioethics and Research Ethics" 27-30 August 2017, Damascus, Syrian Arab Republic (http://www.unesco.org/new/en/syria-crisis-response/regional-response/single-view/news/unesco_beirut_promotes_ethics_ teaching_and_research_in_syri/).

\section{State of Kuwait Prize for the Control of Cancer, Cardiovascular Diseases and Diabetes in the Eastern Mediterranean Region}

The State of Kuwait Prize for the Control of Cancer, Cardiovascular Diseases and Diabetes in the Eastern Mediterranean Region is one of several Foundation awards, administered by the World Health Organization, to acknowledge the work of well-known scientists, researchers or dedicated people who have made an outstanding contribution in prevention, control or research in one or more of the following disease groups: cancer, cardiovascular disease and diabetes.

The prize consists of a bronze medal and a sum of money, which is presented at the WHO Regional Committee for the Eastern Mediterranean by the Committee's Chairman.

More information about the eligibility criteria and access to the online application form is available at: http://kuwaitprize. emro.who.int/ 